International Journal of Tropical Medicine 7 (1): 6-16, 2012

ISSN: 1816-3319

(C) Medwell Journals, 2012

\title{
Area-Based Socioeconomic Conditions and Urban Malaria and Diarrhea Mortalities in Accra, Ghana
}

\author{
${ }^{1-3}$ Julius N. Fobil, ${ }^{1}$ Wibke Loag, ${ }^{1}$ Norbert Schwarz, ${ }^{5}$ Frederick Rodrigues, \\ ${ }^{2}$ Christian G. Meyer, ${ }^{3}$ Alexander Kraemer and ${ }^{1}$ Juergen May \\ ${ }^{1}$ Infectious Disease Epidemiology, ${ }^{2}$ Department of Molecular Medicine, \\ Bernhard Nocht Institute for Tropical Medicine, \\ Bernhard Nocht Str. 74 D-20359 Hamburg, Germany \\ ${ }^{3}$ Department of Public Health Medicine, School of Public Health, \\ University of Bielefeld, P.O. Box 100131, D-33501 Bielefeld, Germany \\ ${ }^{4}$ Department of Biological, Environmental and Occupational Health Sciences, \\ School of Public Health, University of Ghana, P.O. Box LG13, Legon, Ghana \\ ${ }^{5}$ Department of Biochemistry, University of Ghana, P.O. Box LG54, Legon, Ghana
}

\begin{abstract}
Health inequalities are linked to inequalities in Socioeconomic Status (SES). While infant malaria/diarrhea mortality is widely studied, not very much is known about the influence of area-based measures of SES and all age urban malaria and diarrhea mortalities. To assess the relationship between area-based SES and malaria/diarrhea mortalities and whether these differed across SE-classes in an urban area in a low income country. Proportional mortality rates, computed from 24716 reported death records, collected from Accra over the period 1998-2002 were compared with area-based socioeconomic data in multivariate linear regression analyses in an ecological study design. While malaria mortality showed strong evidence of significant differences across the SE-quintiles $\left(\mathrm{Mean}_{\mathrm{PMR}}=0.030 ; 95 \% \mathrm{CI}=0.0100 .049 \mathrm{p}=0.0008\right)$, no such differences in diarrhea mortality were observed $\left(\mathrm{Mean}_{\mathrm{PMR}}=0.027 ; 95 \% \mathrm{CI}=0.0140 .040 ; \mathrm{p}=0.288\right)$. Analyses showed weaker associations between area-based SE-conditions and diarrhea mortality than that observed for malaria mortality. We conclude that all age urban malaria mortalities were more sensitive to changing area-based SE-conditions than diarrhea mortalities suggesting perhaps that social interventions were more effective in diarrhea control compared to malaria.
\end{abstract}

Key words: Accra, area-based SES, SE-quintiles, health inequalities, proportional mortality ratio, Germany

\section{INTRODUCTION}

Over the past decades, cities in many low income economies and in Africa have experienced a remarkable and unprecedented population growth with accompanying deep stagnation or even shrinkage in their economies over the same period (Todaro, 1997). Although, the rate of population growth may have declined slightly in recent years due to a moderate decline in urban fertility rate, urban areas in these regions have remain foci of both economic shocks and social instability because of dwindled employment opportunities, falling wages and contracting social services (Todaro, 1997; Robins et al., 2005). Moreover, the urban economies in these settings are still characterized by rapid structural changes much worse than their equally highly unstable national political economies (Robins et al., 2005; Roemer, 1980). These poor developments have fostered sustained scarcity of food and lack of shelter which together with reduction in other social protection opportunities have spelled further doom for urban residents in these areas (Kutzin, 2001).

By 1990 , the poorest quintile of the population in Ghana had received only $12 \%$ of the benefit of using public health services allowing the richest quintiles to receive $33 \%$ and thus widening inequalities of access to healthcare (Arhin-Tenkorang, 2001; Asenso-Okyere et al., 1998; McIntyre et al., 2008; Awoonor-Williams et al., 2004).

Whereas the impact of the inequalities on child mortality has been widely studied, their impact on all age mortality has been neglected (Pence et al., 2007; Brockerhoff and Hewett, 2000; Kirk and Pillet, 1998; Benefo and Schultz, 1996; Tawiah, 1989; Berger et al., 2008; Pence et al., 2007). Key questions emanating from the lack of research on this aspect of urban health

Corresponding Author: Julius N. Fobil, Bernhard Nocht Institute for Tropical Medicine, Bernhard Nocht Str. 7420359 Hamburg, Germany 
therefore include: do the area-based measures of SES represent good metrics for use in studying health inequalities in the absence of individual level measures and what is the direction and magnitude of the association between area-based measures of SES and malaria/diarrhea mortalities in rapidly urbanizing areas in low income settings?

In this analysis, we did not only assess whether or not all age urban malaria and diarrhea mortalities differed across socioeconomic class but we also assessed the association between area-based SES and the all age malaria and diarrhea mortalities in a rapidly urbanizing setting in a low income economy. The overall goal of the effort was then to assess the direction and magnitude of the association between area-based socioeconomic conditions and the observed all age urban malaria and diarrhea mortalities in a rapidly urbanizing area in a developing economy. The multiple tasks undertaken to achieve the set objectives of the study were:

- To construct a uni-dimensional measure of areabased socioeconomic conditions from a large number of socioeconomic variables and based upon the uni-dimensional variable, create wealth quintiles for the study area
- To compute a valid mortality outcome measure from the routine death records

- To investigate the relationship between malaria and diarrhea mortality and area-based socioeconomic measures through multilevel analysis of the mortality outcomes across social class or socioeconomic quintiles

\section{MATERIALS AND METHODS}

Study area: This analysis was conducted in Accra, the capital city of Ghana (Fig. 1) which occupies a total land area of 238,537 $\mathrm{km}^{2}$ and had a total population of 18.9 million in 2000 (GSS, 1970, 2000). The Accra Metropolitan Area (AMA) is the largest of Ghana's leading urbanized centers with an estimated population of approximately 1.7 million in 1990 and 2.7 million in 2000 (Fobil et al., 2008). It harbors $>30 \%$ of the urban population and nearly $15 \%$ of the country's total population (Fobil et al., 2010).

Study design and data collection: The Accra metropolitan Area consists of 1700 Enumeration Areas (EAs) drawn up for the 2000 National Population and Housing Census

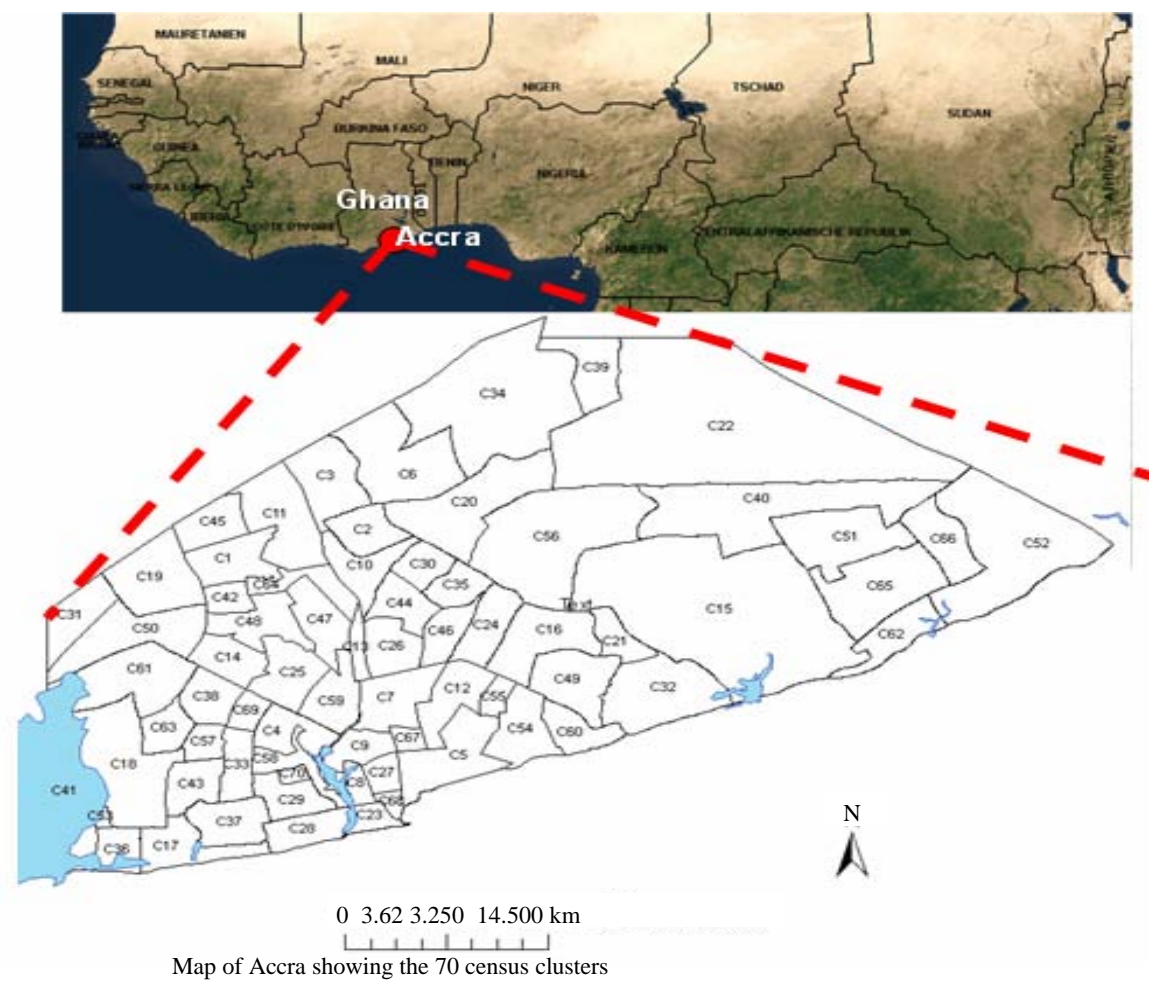

Fig. 1: Map of Accra (the study area) situated within the geographic coordinates of Ghana and West Africa. The maps shows the 70 census clusters to which death events were linked and from for the environmental variables were obtained 
survey. For purposes of this study, not only geographically contiguous EAs but also EAs with similar population characteristics were merged to produce census clusters or localities according to the sampling frame used by Ghana's Statistical Service in the 2000 national population census (Fobil, 2011; GSS, 2002). These clusters contrast with those used in the Ghana Demographic and Health Survey (GDHS) in that the GDHS clusters are merely sampling points which may be conterminous with a one census cluster or combine two or more census clusters or in some cases an overlap of several census clusters (GSS, 2008). However, the GDHS provides comparable data for long-term trend analysis in Ghana since surveys were implemented by the GSS using similar data collection procedures as the censuses. For example GDHS utilizes a two-stage sample design (GSS, 2004, 2008). The first stage involves selecting sample points or clusters from an updated master sampling frame constructed from the 2000 Ghana population and housing census. During the 2008 GDHS for instance, a total of 412 sampling points were selected using systematic sampling based on a probability which was proportional to size of the sampling points (GSS, 2008).

In this study, the boundaries of the census clusters were digitized into polygons which together formed a complete digital map of urban Accra (Fig. 1). In the digitization process, we made use of hardcopy toposheets, some of which were drawn to scale while others were not (Fobil, 2011; GSS, 2002). The toposheets that were drawn to scale were in the scale of 1:2500 resolutions and were in forms ready for direct digitization. This was done by plotting and registering 4 points or codes (geo-codes) of 4 physical landmarks (arranged in a rectangle) identified on the hardcopy maps into a computer which was connected to a digitizer in MapInfo environment and transferred into ArcView for further editing. Two approaches were used in creating the polygons of census clusters.

In the first procedure, researchers identified 4 key features or landmarks on the maps based on the census description of the enumeration areas. Coordinates (geo-codes) [x-y coordinates] of the physical landmarks were then taken using a Geographic Positioning System (GPS). These were plotted and registered in a rectangular frame in MapInfo which was installed on a computer connected to a digitizer. The rectangles were used as reference points for various boundary lines to be traced by a digitizer.

In the procedure, we identified fours points (forming a rectangle) on a map already drawn to scale but which were also found on the maps that were not drawn to scale. The scaled-maps were used as a base-maps or standards from which geo-referenced points were projected onto the non-scaled maps (i.e., maps not drawn to scale). The projected geo-referenced points then formed rectangles on the non-scaled maps. The rectangles were plotted and registered into a computer connected to a digitizer which enabled all cluster boundary lines to be traced in the same manner as was done in the first procedure. To validate the two procedures, we superimposed the maps produced from the separate approaches (Fobil et al., 2010; Fobil, 2011). A perfect overlap was evidence of consistency and proof of validity of the two processes (Fobil, 2011). The census clusters were employed in this study as the basic units of the analysis (GSS, 2002, 2004).

Area-based socioeconomic variables: The census 2000 database held several cluster level measures of socioeconomic status including educational attainment, literacy rate, school enrolment, religion, ethnicity, marital status, employment status, type of employment and economic activity status (e.g., weather employable or not). There were 53 of these socioeconomic variables in total (Fobil et al., 2010) and were grouped under 4 main categories as:

\section{- Economic activity status}

- Educational attainment

- Occupation

- Place of work

- Marital status

- Ethnicity

In this study, marital status and ethnicity categories were excluded because they were not fully aligned with socioeconomic considerations and were therefore not considered good proxy measures of SES. We explored the remaining 39 variables using Principal Component Analysis (PCA) in Stata Version 9.0 (developed by StataCorp, College Station, TX USA) to determine their relationships with each other and to be able to develop a uni-dimensional measure of SES e.g., socioeconomic zones (quintiles) for the study area (Fobil et al., 2010). The variables used in constructing the area-based socioeconomic measures were computed as a proportion of individuals with a given socioeconomic characteristic in a cluster (Table 1). An area-based measure of socioeconomic conditions defines the overall social status of a given area in contrasts to individual level SES which defines the social status of an individual. These area-based measures were used as proxies for cluster level socioeconomic conditions in lieu of the traditional or conventional measures of SES such as household incomes, asset-based indices, consumption or expenditure 
Int. J. Trop. Med., 7 (1): 6-16, 2012

Table 1: The characteristics of the SES variables used in the PCA model

\begin{tabular}{|c|c|c|c|c|c|c|}
\hline Variables & Obs. & Mean proportion & Factor score & $\mathrm{SD}$ & Min. & Max. \\
\hline Employable & 69 & 0.611 & 0.500 & 0.077 & 0.137 & 0.750 \\
\hline Employed & 69 & 0.861 & 0.500 & 0.041 & 0.690 & 0.942 \\
\hline Pre-school education & 70 & 0.044 & 0.448 & 0.008 & 0.013 & 0.059 \\
\hline Primary education & 70 & 0.165 & 0.520 & 0.027 & 0.031 & 0.220 \\
\hline Middle/JSS education & 70 & 0.165 & 0.520 & 0.027 & 0.031 & 0.220 \\
\hline Residents with tertiary education & 70 & 0.076 & -0.451 & 0.096 & 0.018 & 0.790 \\
\hline Administrative and managerial occupations & 70 & 0.014 & 0.419 & 0.016 & 0.001 & 0.095 \\
\hline Clerical and related occupations & 70 & 0.135 & 0.459 & 0.029 & 0.059 & 0.208 \\
\hline Service occupations & 70 & 0.122 & -0.490 & 0.067 & 0.059 & 0.482 \\
\hline Agriculture/husbandry/forestry/fishing/hunting occupation & 70 & 0.042 & 0.356 & 0.047 & 0.008 & 0.249 \\
\hline Proportion of other laborers not elsewhere classified & 70 & 0.237 & -0.415 & 0.047 & 0.119 & 0.365 \\
\hline Residents working in manufacturing & 70 & 0.169 & -0.415 & 0.031 & 0.089 & 0.223 \\
\hline Residents working in wholesale/retail trade/vehicle repairers & 70 & 0.264 & -0.483 & 0.081 & 0.081 & 0.450 \\
\hline Residents working in transport storage and communications & 70 & 0.093 & -0.320 & 0.026 & 0.032 & 0.148 \\
\hline Residents working in public administration/defense/social security & 70 & 0.074 & 0.357 & 0.087 & 0.013 & 0.467 \\
\hline Residents working in private households & 70 & 0.026 & 0.401 & 0.027 & 0.003 & 0.170 \\
\hline $\mathrm{PMR}_{\mathrm{fd}}$ for malaria & 70 & 0.054 & - & 0.022 & 0.008 & 0.121 \\
\hline $\mathrm{PMR}_{\mathrm{fd}}$ for diarrhea & 70 & 0.043 & - & 0.014 & 0.012 & 0.092 \\
\hline
\end{tabular}

indices, etc. because they can be more reliably measured compared to the traditional counterparts. For instance while most people feel reluctant to talk about incomes and earnings, often forget household expenditures and may not be reporting correct income levels, it is fairly easy to accurately count the number of unemployed or those in employment or economically active and economically inactive people in a survey (Brydon, 1999; Hanson et al., 2009; Uchudi, 2001; Vyas and Kumaranayake, 2006). For this reason, the measures of economic status adopted in this study seem more reliable compared to the conventional ones. The measures have also been employed to assess the association between urban environmental quality conditions and urban socioeconomic conditions in Accra, Ghana (Fobil et al., 2010).

Health data collection and summary measure estimation: The health data (all-cause deaths) were obtained from the Ghanaian Vital Registration System (VRS) over a 5 years period spanning 1998-2002. The total number of deaths recorded in the registers over this period in urban Accra was 24716 . From an original excel database, these death records were exported into Stata Version 9 for cleaning and cluster allocation. The reference point for cluster allocation of deaths was the place of address (i.e., the house address of the normal place of residence prior to death).

From the routine death records, the fraction of cluster level deaths was calculated separately for both malaria and diarrhea on the basis of the assumptions relating the calculation of Proportional Mortality Ratio (PMR) (Aveyard, 1998) in Eq. 1. A PMR for a particular disease is the observed proportion of deaths due to that cause in an exposed population over the expected proportion (Aveyard, 1998). The expected proportion is the number of deaths in a reference population due to the specific cause over all deaths in that population. In this study, the reference population was the city level population of Accra and instead of population numbers; we used the city-level reported death events for the computation. Deriving the fraction of cluster level deaths from the PMR, the metric took into account the data quality issues such as incompleteness death registration and misclassification. A mathematical expression for computing PMR is given by:

$$
\mathrm{PMR}=\frac{\mathrm{D}_{\mathrm{Pn}} / \mathrm{A}_{\mathrm{Fn}}}{\mathrm{D}_{\mathrm{Pr}} / \mathrm{A}_{\mathrm{FF}}}
$$

Where:

$\mathrm{D}_{\mathrm{Pn}}=$ Number of deaths from a specific disease D in population $\mathrm{Pn}$

$A_{\mathrm{Pn}}=$ Number of deaths from all diseases in population $\mathrm{Pn}$

$D_{\mathrm{Pf}}=$ Number of deaths from a specific disease $\mathrm{D}$ in a reference population $\mathrm{Pf}$

$\mathrm{A}_{\mathrm{Pf}}=$ Number of deaths from all diseases in a reference population Pf

In linear regression analyses, proportions tend to be more appropriate than ratios for assessing linear relationships and as the interest in this study was to compare mortality in different clusters (e.g., clusters C1-C3, etc.), we decomposed Eq. 1 to obtain the fraction of cluster level deaths due to a specific cause (i.e., malaria or diarrhea). This was achieved simply via multiplying Eq. 1 by the expected proportion of deaths $\left(D_{\mathrm{Pf}} / \mathrm{A}_{\mathrm{Pf}}\right)$ which is given as:

$$
\mathrm{PMR}_{\mathrm{fd}}=\frac{\mathrm{D}_{\mathrm{pr}}}{\mathrm{A}_{\mathrm{Pu}}}
$$

where, $\mathrm{PMR}_{\mathrm{fd}}$ is the fraction of cluster level deaths due to a specific cause (malaria/diarrhea in this case). 
Analytical approach: In the exploratory analyses, 39 different socioeconomic variables from the census 2000 database were used after 14 of them were removed by excluding the marital status and ethnicity categories. In order to detect and deal with multicollinearity, we conducted correlation analysis and assessed the Variance Inflation Factor (VIF) for all variables and thus modified and/or removed redundant variables before the final analyses.

PCA methods were used to reduce the yet still large number of socioeconomic variables into a uni-dimensional variable from which socioeconomic quintiles were created. We then assessed whether there were differences in malaria and diarrhea mortality across the socioeconomic classes i.e., the wealth quintiles created. In reducing the number of variables to a manageable uni-dimensional variable, we run PCA of all the 39 variables (Fobil et al., 2010). The 16 variables which had strong loading (i.e., those with factor scores of $|0.3|$ and above) were retained while those with poor loading were removed from the final PCA model that was used to develop the uni-dimensional measure (Vyas and Kumaranayake, 2006). The scores of 16 SES variables were employed in the final PCA model which produced a total of 16 uni-directional components (comp1-comp3, etc., Table 2). Using the uni-directional components, socioeconomic quintiles were developed for the study area (Fobil et al., 2010). In the development of the SE-quintiles, factor score with a low value represented high socioeconomic status and that for high factor score indicated low socioeconomic status. The final output from the PCA model showed 16 corresponding components with component 1 (compl) explaining 33.9\% of the variation in socioeconomic conditions in the study area (Table 2). Overall, 5 components (comp1-comp5)

Table 2: Uni-directional components from PCA model of 69 variables

\begin{tabular}{lcccc}
\hline & Principal comp onents/correlation & & \\
Component & Eigenvalue & Difference & Proportion & Cumulative \\
\hline Comp1 & 5.427 & 2.634 & 0.339 & 0.339 \\
Comp2 & 2.794 & 0.716 & 0.175 & 0.512 \\
Comp3 & 2.077 & 0.352 & 0.130 & 0.644 \\
Comp4 & 1.725 & 0.557 & 0.108 & 0.751 \\
Comp5 & 1.168 & 0.404 & 0.073 & 0.824 \\
Comp6 & 0.764 & 0.106 & 0.048 & 0.872 \\
Comp7 & 0.658 & 0.109 & 0.041 & 0.913 \\
Comp8 & 0.550 & 0.262 & 0.034 & 0.948 \\
Comp9 & 0.288 & 0.084 & 0.018 & 0.966 \\
Comp10 & 0.204 & 0.082 & 0.013 & 0.978 \\
Comp11 & 0.122 & 0.023 & 0.008 & 0.986 \\
Comp12 & 0.098 & 0.030 & 0.006 & 0.992 \\
Comp13 & 0.068 & 0.033 & 0.004 & 0.996 \\
Comp14 & 0.035 & 0.013 & 0.002 & 0.999 \\
Comp15 & 0.022 & 0.022 & 0.001 & 1.000 \\
Comp16 & 0.001 & - & 0.000 & 1.000 \\
\hline Rotation & & &
\end{tabular}

Rotation: (unrotated $=$ principal); Number of obs $=69$; Number of comp $=$ $15 ;$ Trace $=16 ;$ Rho $=1.000$ were significant and accounted for up to $82.4 \%$ of the total variation in the socioeconomic conditions (Table 2). However, in constructing the socioeconomic classes, we relied solely upon compl which was responsible for the largest variation in the overall socioeconomic conditions, i.e., accounted for approximately $34 \%$ of the total variation as suggested by Vyas and Kumaranayake (2006).

\section{RESULTS AND DISCUSSION}

In total, 24716 death events occurred in urban Accra out of which $1292(5.2 \%)$ and 1001 (4.1\%) were deaths attributed to malaria and diarrhea, respectively $>5$ years period (1998-2002). In order to analyze the relationship between area-based SES and urban malaria as well as diarrhea mortality in Accra, the fraction of cluster level mortality due to a specific cause $\left(\mathrm{PMR}_{\mathrm{fid}}\right)$ and the Relative Mortality (RM) for malaria and diarrhea across SES quintiles were calculated (Table 3). While there was strong evidence of an overall difference in the fraction of deaths due to malaria across the socioeconomic quintiles $(p<0.001)$, no such evidence of an overall difference in the fraction of deaths due to diarrhea was observed across the SES quintiles $(\mathrm{p}=0.288)$. In the inter-quintile analyses, no evidence of a difference (RM 0.88, $\mathrm{p}=0.725$ ) in malaria mortality was observed between the richest class (Mean $\mathrm{PMR}_{\mathrm{fd}}=0.030$, CI 0.010-0.049) and the upper middle class $\left(\right.$ Mean $\mathrm{PMR}_{\mathrm{fd}}=0.026$, CI 0.013-0.039).

In contrast, there was evidence of a doubled risk in malaria-related death in the middle class (RM 1.99, $\mathrm{p}=0.006)$ and the poorest class $(\mathrm{RM}=2.01, \mathrm{p}=0.018)$ although, the upper middle class $(\mathrm{RM}=1.71, \mathrm{p}=0.087)$ did not show such evidence. Compared to malaria mortality, no evidence of a significant difference was observed in any of the SE-quintiles for diarrhea mortality (Table 3) although, as a tendency, the richest class had a decreased risk of diarrhea-related mortality compared to the other classes (e.g., 1.5 times lower risk compared to the poorest class) which had approximately the same mortality risk levels.

In order to investigate the magnitude and direction of the relationship between area-based socioeconomic measures and urban malaria/diarrhea mortality, we conducted further bi-variate and multi-variate regression analyses. After controlling for all other measures of SES in a multi-variate regression, four (the proportion of residents with vocational, technical and commercial education, the proportion electricity of gas and water supply sector workforce, proportion of education sector workforce and the proportion of residents with tertiary education) variables showed strong evidence of 
Int. J. Trop. Med., 7 (1): 6-16, 2012

Table 3: Socioeconomics and malaria/diarrhea mortality inequality

\begin{tabular}{llccll}
\hline Health variable (mortality) & SES quintiles $^{\mathrm{a}}$ & Mean PMR $_{\mathrm{fd}}{ }^{\mathrm{b}}$ & $\mathrm{Cl}^{\mathrm{c}}$ & $\mathrm{RM}^{\mathrm{d}}$ & $\mathrm{p}$-value \\
\hline Malaria & Richest class & 0.030 & $0.010-0.049$ & 1.00 & Overall $\mathrm{p}<0.001$ \\
& Upper middle class & 0.026 & $0.013-0.039$ & 0.88 & 0.725 \\
& Middle class & 0.059 & $0.049-0.069$ & 1.99 & 0.006 \\
& Lower middle class & 0.051 & $0.035-0.067$ & 1.71 & 0.087 \\
Diarrhea & Poorest class & 0.060 & $0.043-0.077$ & 2.01 & 0.018 \\
& Richest class & 0.027 & $0.014-0.040$ & 1.00 & Overall $\mathrm{p}=0.288$ \\
& Upper middle class & 0.063 & $0.015-0.112$ & 2.34 & 0.156 \\
& Middle class & 0.041 & $0.033-0.049$ & 1.52 & 0.060 \\
& Lower middle class & 0.037 & $0.024-0.050$ & 1.37 & 0.262 \\
& Poorest class & 0.041 & $0.028-0.054$ & 1.51 & 0.122 \\
\hline
\end{tabular}

aSES: Socioeconomoc Status quintiles assessed by principle component analysis; PMR $_{\mathrm{fd}}$ : fraction of cluster level deaths due to a specific cause; CI, $95 \%$ confidence interval; ${ }^{\mathrm{R}} \mathrm{RM}$ : Relative Mortality (quotient of mean $\mathrm{PMR}_{\mathrm{fd}}$ in each class over that in the richest class), ${ }^{\mathrm{p}} \mathrm{p}$-values reported were obtained from Student $\mathrm{t}$-test while the overall ones reported in the abstract were obtained by ANOVA

Table 4: Association between area-base SES and the fraction of deaths due to malaria malaria and diarrhea

\begin{tabular}{|c|c|c|c|c|}
\hline Variables & SES variable ${ }^{a}$ & Coefficient $^{b}$ & $95 \% \mathrm{CI}^{c}$ & $\mathrm{p}$-value \\
\hline \multirow[t]{5}{*}{ Fraction of deaths due to malaria } & Basis (intercept) ${ }^{\mathrm{d}}$ & 0.10 & $0.06-0.13$ & $<0.001$ \\
\hline & Proportion of residents with vocational, technical and commercial education & -0.49 & $-0.81-0.18$ & 0.003 \\
\hline & Proportion of electricity, gas and water supply sector workforce & -2.27 & $-3.68-0.86$ & 0.002 \\
\hline & Proportion of education sector workforce & 0.95 & $0.47-1.43$ & $<0.001$ \\
\hline & Proportion of residents with tertiary education & -0.42 & $-0.10-0.24$ & $<0.001$ \\
\hline Fraction of deaths due to diarrheae & Basis (intercept) ${ }^{\mathrm{f}}$ & 0.04 & $0.03-0.05$ & $<0.001$ \\
\hline
\end{tabular}

${ }^{a}$ SES: Socioec onomic Status quintiles assessed by principle component analysis; ${ }^{b}$ Unit increase of the disease-specific fraction of deaths per unit increase of the SES variable; ${ }^{\circ}$ Confidence interval; ${ }^{d}$ Basic fraction of deaths due to malaria; ${ }^{e}$ None of the area-based SES variables showed evidence of association with the fraction of deaths due to diarrhea; ${ }^{\text {B }}$ asic fraction of deaths due to diarrhea

association at multi-variate level (Table 4). On the contrary, there was no evidence of any association between the area-based measures of SES and the cluster level fraction of deaths due to diarrhea at both bi-variate and multi-variate levels.

Only two of the area-based measures of SES (the proportion of residents with vocational, technical and commercial education and the proportion of electricity, gas and water supply sector workforce) showed evidence of association with the fraction of deaths due to malaria at the bi-variate level (Fig. 2). First, a unit increase in the proportion of residents at the level of vocational, technical and commercial education led to a significant decrease (coefficient $=-0.45$; CI-0.75 to $0.15, \mathrm{p}=0.004)$ in the cluster level fraction of deaths due to malaria (Fig. 2a). The amount of the variation explained by the proportion of residents at the level of vocational, technical and commercial education at bivariate level was $14 \%\left(\mathrm{R}^{2}=0.14\right)$. The association between two variables was even stronger (coefficient $=-0.49$ : $95 \% \mathrm{CI}$ : $-0.81-0.18$, $p=0.003$ ) at multivariate level (Table 4). In contrast while no evidence of association (coefficient $=0.07 ; 95 \% \mathrm{CI}$ : $-1.901 .91, p=0.994$ ) was observed between the fraction of deaths due to malaria and the proportion of electricity, gas and water supply sector workforce at bivariate level (Fig. 2b) at multivariate level however, a strong evidence of association (coefficient $=-2.27 ; 95 \%$ CI: $-3.68-0.86$, $\mathrm{p}=0.002$ ) was observed between the two variables.

Similarly, whereas in bivariate analysis, no evidence of association (coefficient $=-0.06 ; 95 \%$ CI: -0.210 .09 , $\mathrm{p}=0.423$ ) was observed between the fraction of deaths due to malaria and the proportion of education sector workforce (Fig. 2c), a very strong evidence of association was observed between the two variables at multivariate level with a unit increase in the proportion of education sector workforce leading to a corresponding increase in the fraction of deaths due to malaria at cluster level (coefficient $=0.95 ; 95 \%$ CI: $0.471 .43 ; \mathrm{p}<0.001$ ).

In the end, an inverse relationship was observed between the fraction of cluster level deaths due to malaria and the proportion of urban population with tertiary education. Although, a very strong evidence of association was observed between the proportion of urban population with tertiary education and urban malaria mortality (coefficient $=-0.42 ; 95 \% \mathrm{CI}:-0.60-0.24$; $\mathrm{p}<0.001$ ) at multivariate level, there was no evidence of association (coefficient $=-0.05 ; 95 \%$ CI: -0.110 .006 , $\mathrm{p}=0.076$ ) between the two parameters at bivariate level (Fig. 2d).

In literature, studies which have explored the relationship between socioeconomic inequalities and health have varied widely in approach in relation to the nature and type of the socioeconomic variables and the type of health outcomes investigated (Page et al., 2009; Conway et al., 2009; Payne and Maxwell, 2009; Zeka et al., 2008; Metcalf et al., 2008).

While most documented studies have examined the role of individual level socioeconomic inequalities in determining the status of human health in a variety of settings and across several health outcome measures (Hanson et al., 2009; Zheng, 2009; Yiengprugsawan et al., 2009; Gagnon and Mazan, 2009; Furst et al., 2009; 

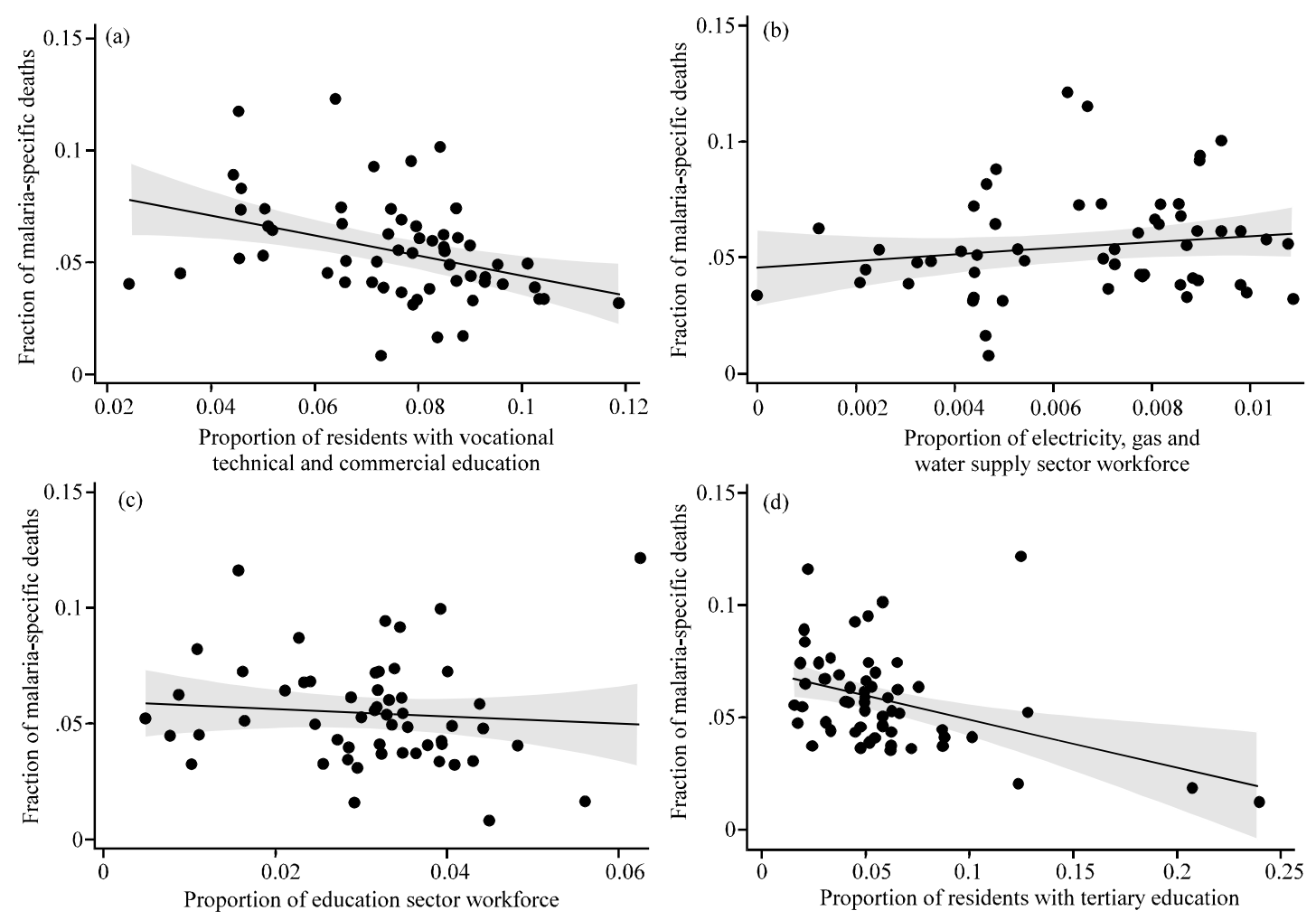

Fig. 2: The nature of the bivariate associations between the health outcome measure (malaria mortality) and the explanatory variables significantly associated in the multivariate analysis (area-based measures of SES) showed in Table 4 and 1 . The points represent the fraction of deaths due to malaria and the proportion of the area-based measures of SES. The solid lines represent the regression line of best fit and the grey area represents their Confident Intervals (CIs); a) the proportion of residents with vocational, technical and commercial education as a function of the fraction of cluster level deaths due to malaria; b) the proportion of electricity, gas and water supply sector workforce as a function of the fraction of cluster level deaths due to malaria; $\mathrm{c}$ ) the proportion of education sector workforce as a function of the fraction of cluster level deaths due to malaria and d) the proportion of residents with tertiary education as a function of the fraction of cluster level deaths due to malaria

Chang et al., 2009; Al-Taiar et al., 2009; Taylor et al., 2008) the focus has been on chronic diseases and their mortalities. Moreover while some of the studies have examined $\mathrm{SE}$ inequalities in relation to their role in driving health inequalities, those studies have focused mainly on individual level socioeconomic factors to the glaring neglect of the effects on health inequalities of area-based measures of socioeconomic conditions (Regidor et al., 2008; Pascual et al., 2007; Subramanian et al., 2006; Geronimus, 2006; Southern et al., 2002; Krieger et al., 2002; Reimers and Laflamme, 2007). Although, infectious diseases have been reported to exhibit significant spatial clustering; especially malaria and diarrhea of the few studies reported in literature none has explored the association between area-based measures of socioeconomic status and malaria and diarrhea mortalities (Schaetti et al., 2009; Raso et al., 2009; Somi et al., 2008; Pande et al., 2008; Kreuels et al., 2008; Genser et al., 2008).
In this study, the relationship between several areabased measures of SES and the fraction of deaths due to malaria and diarrhea was explored in Accra in linear multiple regression analyses. Despite the deepened socioeconomic inequality gaps across the social classes in Accra, mortality inequality gaps have decreased for both malaria and diarrhea but more so for diarrhea than for malaria mortality. The inter-quintile mortality differentials were smaller in the case of diarrhea mortality than in the case of malaria mortality, suggesting that social interventions had more impacts on diarrhea than on malaria mortality inequality. An alternate explanation of this observation could be that despite a demonstrable promise for their use in predicting urban malaria mortality, the area-based measures of SES had no conceivable linear relationship with the urban diarrhea mortality at aggregate levels. Additionally while it was observed that many of the area-based measures of SES did not show evidence of 
association with urban malaria at bivariate level, a reasonable number showed strong evidence of association with urban malaria mortality at multivariate level, very much consistent with similar studies reported in literature (Furst et al., 2009; Al-Taiar et al., 2009; Hulden and Hulden, 2009). The contrast between bivariate and multivariate level observations suggests that the interaction of area-based measures may be both synergistic (i.e., reinforce one another) and antagonistic (i.e., demonstrate opposing effects) depending on whether viewed at individual level or aggregate level and that confounding factors could mask associations when not corrected for in multivariate analyses.

Moreover, there were remarkable non-uniformities in the risk of mortality for both malaria and diarrhea among the different socioeconomic quintiles. The highly irregular pattern of inter-quintile mortality differentials for urban malaria and diarrhea mortality was perhaps due to the fact that the socioeconomic factors alone did not explain the observed inter-quintile mortality gaps. It was likely that other factors such as lifestyle, differences in health seeking behavior, traditional beliefs and taboos might have accounted for the inter-quintiles mortality anomalies observed across the SE-classes.

Out of the large number of area-based measures of socioeconomic conditions explored, only four showed strong evidence of association with urban malaria mortality. For instance increase in the proportion of individuals with vocational, technical, commercial and tertiary education led to a decrease risk of urban malaria mortality in the given area. This could be due to the fact that urban areas with individuals in these categories were probably more likely to take malaria preventive and treatment measures more seriously compared to areas with high proportion of education sector workforce. This observation provides clues that the inclusion of these measures of SES as potential risk factors for urban malaria mortality in future case-control studies aimed to determine city-wide distribution of risks for urban malaria mortality at both household and community levels is important. Finally, urban areas with high proportion of electricity, gas and water supply sector workforce tended to be associated with higher urban malaria mortality and provide clues that those areas may constitute important hotspots and zones of vulnerability to urban malaria mortality. This in turn provides clues for appropriate targeting of scarce resources in those areas if urban malaria control programs were to be cost-effective. We could however not establish causal evidence of this assertion because the data used were not available at individual level.

\section{CONCLUSION}

This study shows that while the area-based measures of SES are perhaps important factors for all-age urban malaria/diarrhea mortalities, their influence on malaria mortality differed considerably from that on urban diarrhea mortality. In addition, the observed nonuniformities in the inter-quintile relative mortality differentials were perhaps more likely a consequence of individual level lifestyle factors and individual differences in health seeking behavior than the influence of socioeconomic inequalities. We therefore concluded that although all-age urban malaria mortalities were more sensitive to changing area-based SES-conditions than diarrhea mortalities, their overall influence on both mortalities was significant and should be taken into account when designing social interventions for infectious control in areas of rapid urban transformation in low income settings. As a recommendation for future research on this subject, we suggest the use of ordinary frailty or geostatistical models to adjust for spatial autocorrelation and to estimate the unmeasured area effects.

\section{LIMITATION}

The data used in this analysis were based on reported deaths which were assigned to clusters on the basis of house address of the normal place of residence prior to death. Errors of house address would lead to cause-ofdeath misallocation which could then affect the study outcome and results. However, such errors would be random in nature and could only result in non-differential biases. Generally speaking although, misdiagnosis is a problem for both malaria and diarrhea, it is more a problem in the diagnosis of malaria (most fever cases may not be malaria but are sometimes taken as malaria) than diarrhea (fairly specific definition passage of $>3$ loose/watery stools per day). Additionally, malaria is typically overdiagnosed in wet season compared to dry season in Ghana. However, we assumed that misdiagnosis was a non-differential error/bias in terms of cluster allocation of death records as it was deemed to affect all census clusters equally i.e., there was no differential misdiagnosis by census cluster. While mortality reporting is generally poor in Ghana, it is a lot better in urban areas compared to rural areas. All deaths except for still-births and some neonatal deaths occurring in urban areas are reported are assigned cause-of-death and place address. In general infant death reporting is less reliable than adult death reporting. Having all these quality issues in mind, we 
explored the range of analytic strategies that would robustly address the inherent data biases. In so doing, $\mathrm{PMR}_{\mathrm{fit}} \mathrm{S}$ were computed as the quotient of specific cause over all-cause so that the effects of the quality issues in both the numerator and the denominator would cancel out. However, an obvious limitation of the metric is that should the risk of mortality for one of the components of all-cause mortality vary by cluster would cause the summary/outcome measure $\mathrm{PMR}_{\mathrm{fd}}$ vary across cluster and may therefore bias the analysis. A way to deal with this problem will be to exclude such components but unfortunately, we did not have the liberty of telling apriori if any of the components of all-cause mortality exhibited differential mortality risk by cluster and therefore this bias could not be controlled for. Another way to deal with this bias will be to use a specific cause of death known to have a uniform risk level across all clusters as the denominator for both the observed proportion and the expected proportion. But then again, this also requires knowledge of risk distribution by cause in the study area and which unfortunately was not available for the study area.

\section{ACKNOWLEDGEMENT}

Funding for this study was generously provided jointly by the Government of Ghana, through the GetFund Scholarship and the German Government through the DAAD Scholarship.

\section{REFERENCES}

Al-Taiar, A., A. Assabri, M. Al-Habori, A. Azazy, A. Algabri, M. Alganadi, C.J. Whitty and S. Jaffar, 2009. Socioeconomic and environmental factors important for acquiring non-severe malaria in children in Yemen: A case-control study. Trans R. Soc. Trop. Med. Hyg., 103: 72-88.

Arhin-Tenkorang, D., 2001. Mobilizing resources for health: The case for user fees revisited. Working paper no. 81. Cambridge, MA: Harvard University.

Asenso-Okyere, W.K., A. Anum, I. Osei-Akoto and A. Adukonu, 1998. Cost recovery in Ghana: Are there any changes in health care seeking behaviour?. Health Policy Plann., 13: 181-188.

Aveyard, P., 1998. A fresh look at proportional mortality ratios. Public Health, 112: 77-80.

Awoonor-Williams, J.K., E.S. Feinglass, R. Tobey, M.N. Vaughan-Smith and F.K. Nyonator et al., 2004. Bridging the gap between evidence-based innovation and national health-sector reform in Ghana. Stud. Fam. Plann., 35: 161-177.
Benefo, K. and T.P. Schultz, 1996. Fertility and child mortality in Cote d'Ivoire and Ghana. World Bank Econ. Rev., 10: 123-158.

Berger, S.G., S.D. Pee, M.W. Bloem, S. Halati and R.D. Semba, 2008. Malnutrition and morbidity among children not reached by the national vitamin a capsule programme in urban slum areas of Indonesia. Public Health, 122: 371-378.

Brockerhoff, M. and P. Hewett, 2000. Inequality of child mortality among ethnic groups in sub-Saharan Africa. Bull World Health Organ., 78: 30-41.

Brydon, L., 1999. With a little bit of luck: Coping with adjustment in urban Ghana, 1975-90. Africa. (Roma), 69: $366-385$.

Chang, J.Y., Locke G.R., C.D. Schleck, A.R. Zinsmeister and N.J. Talley, 2009. Risk factors for chronic diarrhoea in the community in the absence of irritable bowel syndrome. Neurogastroenterol Motil., 21: 1060-1087.

Conway, D.I., A.D. McMahon, K. Smith, R. Black nad G. Robertson et al., 2009. Components of socioeconomic risk associated with head and neck cancer: A population-based case-control study in Scotland. Br. J. Oral. Maxillofac. Surg., 48: 11-17.

Fobil, J.N., 2011. Spatial urban environmental change and malaria and diarrhea mortality in Accra, Ghana. Department of Public Health Medicine. Bielefeld: University of Bielefeld, 230.

Fobil, J.N., J. May and A. Kraemer, 2010. Assessing the relationship between socioeconomic conditions and urban environmental quality in Accra, Ghana. Int. J. Environ. Res. Public Health, 7: 125-145.

Fobil, J.N., N.A. Armah, J.N. Hogarh and D. Carboo, 2008. The influence of institutions and organizations on urban waste collection systems: An analysis of waste collection system in Accra, Ghana (1985-2000). J. Environ. Manage., 86: 262-271.

Furst, T., G. Raso, C.A. Acka, A.B. Tschannen, E.K. Ngoran and J. Utzinger, 2009. Dynamics of socioeconomic risk factors for neglected tropical diseases and malaria in an armed conflict. PLoS Negl. Trop Dis., 3: e513-e513.

GSS, 1970. Ghana Population and Housing Census. Accra: Ghana Statistical Service.

GSS, 2000. Provisional Results of the National Population and Housing Census. Accra: GSS.

GSS, 2002. Population and Housing Census 2000: Summary of Final Results. Accra: Ghana Statistical Service.

GSS, 2004. Preliminary Reports. Ghana Demographic and Health Survey 2003. Accra: Ghana Statistical Service.

GSS, 2008. The Final Report of the Ghana Demographic and Health Survery, 2008. Accra: Ghana Statistical Service, 426. 
Gagnon, A. and R. Mazan, 2009. Does exposure to infectious diseases in infancy affect old-age mortality? Evidence from a pre-industrial population. Soc. Sci. Med., 68: 1609-1616.

Genser, B., A. Strina, L.A. dos Santos, C.A. Teles, M.S. Prado, S. Cairncross and M.L. Barreto, 2008. Impact of a city-wide sanitation intervention in a large urban centre on social, environmental and behavioural determinants of childhood diarrhoea: Analysis of two cohort studies. Int. J. Epidemiol., 37: $831-840$.

Geronimus, A.T., 2006. Invited commentary: Using areabased socioeconomic measures-think conceptually, act cautiously. Am. J. Epidemiol., 164: 835-840.

Hanson, K., T. Marchant, R. Nathan, H. Mponda and C. Jones et al., 2009. Household ownership and use of insecticide treated nets among target groups after implementation of a national voucher programme in the United Republic of Tanzania: Plausibility study using three annual cross sectional household surveys. J. Article, Publ: BMJ Publish. Group, Ltd., 339: 2434-2434.

Hulden, L. and L. Hulden, 2009. The decline of malaria in Finland the impact of the vector and social variables. Malar J., 8: 94-94.

Kirk, D. and B. Pillet, 1998. Fertility levels, trends and differentials in sub-Saharan Africa in the 1980s and 1990s.. Stud. Fam. Plann., 29: 1-22.

Kreuels, B., R. Kobbe, S. Adjei, C. Kreuzberg and C. von Reden et al , 2008. Spatial variation of malaria incidence in young children from a geographically homogeneous area with high endemicity. J. Infect Dis., 197: 85-93.

Krieger, N., J.T. Chen, P.D. Waterman, M.J. Soobader, S.V. Subramanian and R. Carson, 2002. Geocoding and monitoring of US socioeconomic inequalities in mortality and cancer incidence: does the choice of area-based measure and geographic level matter: The Public Health Disparities Geocoding Project. Am. J. Epidemiol., 156: 471-482.

Kutzin, J., 2001. A descriptive framework for country-level analysis of health care financing arrangements. Health Policy, 56: 171-204.

McIntyre, D., B. Garshong, G. Mtei, F. Meheus and M. Thiede et al., 2008. Beyond fragmentation and towards universal coverage: Insights from Ghana, South Africa and the United Republic of Tanzania. Bull World Health Organiz., 86: 871-876.

Metcalf, P.A., R.R. Scragg, D. Schaaf, L. Dyall and P.N. Black et al., 2008. Comparison of different markers of socioeconomic status with cardiovascular disease and diabetes risk factors in the Diabetes. Heart Health Survey. N. Z. Med. J., 121: 45-46.
Page, A., R. Taylor, J. Richters, J. Shaw and J. Taylor et al., 2009. Upstairs and downstairs: Socioeconomic and gender interactions in herpes simplex virus type 2 seroprevalence in australia. Sex Transm Dis., 36: 344-349.

Pande, S., M.A. Keyzer, A. Arouna and B.G. Sonneveld, 2008. Addressing diarrhea prevalence in the West African Middle Belt: Social and geographic dimensions in a case study for Benin. Int. J. Health Geogr., 7: 17-17.

Pascual, C., E. Regidor, P. Astasio, P. Ortega, P. Navarro and V. Dominguez, 2007. The association of current and sustained area-based adverse socioeconomic environment with physical inactivity. Soc. Sci. Med., 65: 454-466.

Payne, R.A. and S.R. Maxwell, 2009.. Deprivation-based risk scores: the re-emergence of postcode prescribing in the UK?. J. Cardiovasc. M ed. (Hagerstown), 10: $157-160$.

Pence, B.W., P. Nyarko, J.F. Phillips and C. Debpuur, 2007. The effect of community nurses and health volunteers on child mortality: The Navrongo Community Health and Family Planning Project. Scand. J. Public Health, 35: 599-608.

Raso, G., K.D. Silue, P. Vounatsou, B.H. Singer, A. Yapi, M. Tanner, J. Utzinger and E.K. Ngoran, 2009. Spatial risk profiling of plasmodium falciparum parasitaemia in a high endemicity area in Cote dlvoire. Malar J., 8: 252-252.

Regidor, E., J.L. Gutierrez-Fisac, E. Ronda, M.E. Calle, D. Martinez and V. Dominguez, 2008. Impact of cumulative area-based adverse socioeconomic environment on body mass index and overweight. J. Epidemiol. Com. Health, 62: 231-238.

Reimers, A. and L. Laflamme, 2007. Hip fractures among the elderly: Personal and contextual social factors that matter. J. Trauma., 62: 365-369.

Robins, C.S., A. Heller and M.A. Myers, 2005. Financial vulnerability among Medicare managed care enrollees. Health Care Financ Rev., 26: 81-92.

Roemer, M.I., 1980. Economics and health policy. WHO Chron, 34: 47-52.

Schaetti, C., R. Hutubessy, S.M. Ali, A. Pach, M.G. Weiss, C.L. Chaignat and A.M. Khatib, 2009. Oral cholera vaccine use in Zanzibar: Socioeconomic and behavioural features affecting demand and acceptance. BMC Public Health, 9: 99-99.

Somi, M.F., J.R. Butler, F. Vahid, J.D. Njau, S.P. Kachur and S. Abdulla, 2008. Use of proxy measures in estimating socioeconomic inequalities in malaria prevalence. Trop. Med. Int. Health, 13: 354-364. 
Southern, D.A., W.A. Ghali, P.D. Faris, C.M. Norris, P.D. Galbraith, M.M. Graham and M.L. Knudtson, 2002. Misclassification of income quintiles derived from area-based measures. A comparison of enumeration area and forward sortation area. Can. J. Public Health, 93: 465-469.

Subramanian, S.V., J.T. Chen, D.H. Rehkopf, P.D. Waterman and N. Krieger, 2006. Comparing individual- and area-based socioeconomic measures for the surveillance of health disparities: A multilevel analysis of Massachusetts births, 1989-1991. Am. J. Epidemiol., 164: 823-834.

Tawiah, E.O., 1989. Child mortality differentials in Ghana: A preliminary report. J. Biosoc. Sci., 21: 349-355.

Taylor, J.C., G.R. Law, P.J. Boyle, Z. Feng and M.S. Gilthorpe et al., 2008. Does population mixing measure infectious exposure in children at the community level? Eur. J. Epidemiol., 23: 593-600.

Todaro, P.M., 1997. Urbanization, unemployment and migration in Africa: Theory and policy. Policy Research Division Working Paper.
Uchudi, J.M., 2001. Spouses socioeconomic characteristics and fertility differences in sub-Saharan Africa: does spouse's education matter?. J. Biosoc. Sci., 33: 481-502.

Vyas, S. and Kumaranayake, 2006. Constructing socioeconomic status indices: how to use principal components analysis. Health policy plann., 21: 459-468.

Yiengprugsawan, V., L.L. Lim, G.A. Carmichael, S.A. Seubsman and A.C. Sleigh, 2009. Tracking and decomposing health and disease inequality in Thailand. Ann. Epidemiol., 19: 800-807.

Zeka, A., S.J. Melly and J. Schwartz, 2008. The effects of socioeconomic status and indices of physical environment on reduced birth weight and preterm births in Eastern Massachusetts. Environ. Health, 7: $60-60$.

Zheng, J., 2009. Achievements and challenges in schistosomiasis control in China. Zhongguo Ji Sheng Chong Xue Yu Ji Sheng Chong Bing Za Zhi, 27: 398-401. 